\title{
LOS CONFLICTOS BIOÉTICOS EN LA INVESTIGACIÓN EN EL ÁREA ODONTOLÓGICA EN EL ECUADOR, UNA MIRADA CRÍTICA
}

\author{
Bioethical Conflicts in Dental Area Research in Ecuador, A Critical View
}

\author{
Victor Montaño Tatés ${ }^{1}$, Wladimir Puruncajas Segarra ${ }^{2}$, Ana Armas Vega ${ }^{3}$ \\ ${ }^{1}$ Odontólogo general, Universidad UTE, Quito - Ecuador. \\ ${ }^{2}$ Arquitecto, Administrador Consultorios Odontológicos, estudiante de maestría de bioética, \\ Universidad Central del Ecuador, Quito. \\ ${ }^{3} \mathrm{PhD}$ en Odontología, Universidad Central del Ecuador, Quito.
}

El compromiso de trabajar por un acceso equitativo a una atención de salud efectiva y de calidad, es un derecho fundamental, para alcanzar el bienestar del individuo, mediante la aplicación de métodos y técnicas basadas con la mejor evidencia científica, respetando la dignidad del individuo mediante políticas públicas adecuadas, tomando como base la Constitución ecuatoriana, que describe a la salud, como derecho innegable, armonizada con el entorno y la naturaleza, con una visión integradora, responsabilidad del Ministerio de Salud Pública del Ecuador, encargado de resolver y tratar problemas sanitarios mediante políticas públicas, servicios eficaces, eficientes, inclusivos y participativos que fomenten la interculturalidad y plurinacionalidad, con procesos y acciones coordinados, de promoción, prevención y prestación de servicios con altos estándares de calidad, respetando la diversidad cultural, religiosa y las necesidades individuales, ejecutadas en un marco bioético.

El modelo de Atención Integral de Salud Familiar, Comunitario e Intercultural (MAIS- FCI), desarrollado por el MSP se reorienta en los últimos años, a un enfoque de promoción y prevención, que poco o nada hacen mención a la salud oral, desestimando una realidad expuesta en el estudio epidemiológico nacional de salud oral realizado en 1996, en la población de entre 5 a 15 años, que evidenció elevados porcentajes de caries dental, incrementados de forma proporcional con la edad de cada individuo. En la década de los 80, diversos países de América Latina, entre ellos Ecuador, incluyeron la fluoración de agua y sal como estrategia de prevención de la caries dental; junto con la eliminación del biofilm mediante el cepillado y el uso de dentífricos con concentraciones de 1000 a 1250 ppm de flúor, asociado al riesgo de desencadenar fluorosis por su ingesta accidental.

El Ecuador, inicia procesos de investigación en el área odontológica, en la década de los 90 con proyectos epidemiológicos transversales, con el apoyo de organizaciones internacionales estructuradas, OPS/OMS, que se complementa con la preparación de especialistas en la investigación, dando paso al único estudio epidemiológico nacional de salud oral en 1996 y al estudio realizado, pero no publicado en el año 2006. 
Buscando mejorar la calidad de los centros académicos de tercer nivel respecto a la formación de profesionales en áreas de la salud, surge un impulso en el desarrollo de proyectos y alianzas entre universidades nacionales e internacionales, dando paso a la formación de profesionales de cuarto nivel con enfoque en investigación y docencia, permitiendo al profesional involucrarse progresivamente en el desarrollo de investigaciones, con varias limitantes en el proceso, asociadas a la falta de normativas sobre lineamientos de regulación de bioética aplicados en investigaciones experimentales, epidemiológicas descriptivas o clínicas de intervención, donde las barreras, burocráticas resultan inquebrantables, asociados a la adquisición de seguro de vida para participantes, aprobación por un comité de bioética sin capacidad de evaluar y emitir un dictamen de estudios odontológicos, con un costo por su análisis que generalmente sobrepasa los recursos existentes para su ejecución.

La Comisión Nacional de Bioética del MSP, creada para velar por el respeto a la dignidad, integridad y derechos, como un punto de reflexión de la autoridad y de quien lo solicite, toma como base el bienestar del individuo, a través de un minucioso análisis, previo a la toma de decisiones; frente a ello, resulta imperioso contar con reformas y nuevos parámetros que flexibilicen el análisis y aprobación de proyectos específicamente en el área de la Odontología, garantizando una consistencia en las políticas públicas. 